\title{
Clinical profile of seizure disorder in hospitalized patients in tertiary care center - A prospective cross-sectional study
}

\author{
Alagu Thiyagarajan $\mathbf{A}^{1}$, Selvakumar $\mathbf{C J}^{2}$, Jenix Nathan $\mathbf{Y A}^{3}$, Ramesh Duraisamy ${ }^{4}$ \\ ${ }^{1,4}$ Senior Assistant Professor, Department of General Medicine, ${ }^{2}$ Assistant Professor, ${ }^{3}$ Post graduate, Department of \\ Neurology, Coimbatore Medical College and Hospital, Coimbatore, Tamil Nadu, India
}

Background: Knowledge regarding people affected with epilepsy is essential for accurate planning and management of patients. This study was conducted to study clinical profile of seizure disorder in the patients hospitalized in a tertiary care hospital of Tamil Nadu. Aims and Objectives: To study clinical profile of seizure disorder in patients hospitalized in Coimbatore government medical college hospital. Materials and Methods: This study was a single center hospital based cross-sectional study of the clinical profile of seizure disorder in hospitalized patients at tertiary care center of Tamil Nadu, Neurology department the 2 years from 2018 to 2020 . All the patients presenting with complaints of seizures were included in this study. Results: This study included a total of 321 patients with epilepsy. Their ages ranged between 10 and 100 years. 180 of the study population were males and 141 were female patients. $30 \%$ of patients had new onset seizures. Fever precipitated seizure in $16 \%$ of the subjects. Excitation, sleep deprivation, fever, watching television, and head trauma showed a strong association with generalized epilepsy. The majority of the patients had generalized tonic-clonic seizure, followed by focal neurological deficit. $98 \%$ of patients responded to treatment and they did not had recurrent episodes of seizure. Conclusion: The sample size of our cohorts is relatively small. It is possible that some prognosis factors may be missed due to the small sample size. Further studies with a larger sample cohort are required. Uneducated and low socioeconomic make people vulnerable to seizures because of lack of awareness, poor compliance to medicines, not detection of seizure provoking factor, repeated exposure to seizure provoking factor, prevalence of alcoholism, and thus lowering seizure threshold. There is a treatment gap still because of epilepsy and appropriate usage of resources will help to reduce this treatment gap and decreases epilepsy associated morbidity and mortality.

Key words: Epilepsy; Focal; Generalized seizures; Generalized; Seizures
Access this article online

Website:

http://nepjol.info/index.php/AJMS

DOI: $10.3126 /$ ajms.v12i12.38877

E-ISSN: 2091-0576

P-ISSN: 2467-9100

Copyright (c) 2021 Asian Journal of Medical Sciences

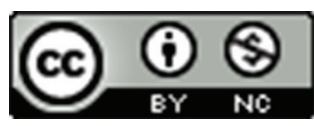

This work is licensed under a Creative Commons Attribution-NonCommercial 4.0 International License.

\section{INTRODUCTION}

Epilepsy is a common medical and social disorder or group of disorders with unique characteristics. Epilepsy was defined conceptually in 2005 as a disorder of the brain characterized by an enduring predisposition to generate epileptic seizures. This definition is usually practically applied as having two unprovoked seizures $>24 \mathrm{~h}$ apart. The International League Against Epilepsy accepted recommendations of a task force altering the practical definition for special circumstances that do not meet the two unprovoked seizures criteria. The task force proposed that epilepsy be considered to be a disease of the brain defined by any of the following conditions: (1) At least two unprovoked (or reflex) seizures occurring $>24 \mathrm{~h}$ apart; (2) one unprovoked (or reflex) seizure and a probability of further seizures similar to the general recurrence risk (at least 60\%) after two unprovoked seizures, occurring over the next 10 years; (3) diagnosis of an epilepsy syndrome. The word "epilepsy" is derived from Latin and Greek words 
for "seizure" or "to seize on." The periodic clinical features of seizures are often dramatic and alarming, and frequently elicit fear and misunderstanding. This, in turn, has led to profound social consequences for sufferers, which has greatly added to the burden of this disease. In ancient times, epileptic attacks were thought to be the result of invasion and possession of the body by supernatural forces, usually malign or evil influences, requiring exorcism, incantations or other religious or social approaches. ${ }^{2}$ Despite scientific advances in the $19^{\text {th }}$ century, epilepsy remained a profound social problem compounded by deeply rooted historical concepts of a supernatural or sacred disorder. ${ }^{3}$ Widespread ignorance, fear, misunderstanding and stigma contributed to severe legal and social penalties. Epilepsy affects people of all ages, both sexes, and all ethnic groups. Children under the age of 2 and adults over 65 are more likely to develop epilepsy than any other age group. This is explained in part by changes that occur in the brains of people early and late in life. During childhood brain development, for example, seizures are not only more likely to occur, they also spread more readily than in a fully developed brain. ${ }^{4}$ The rise in the incidence of epilepsy in adults as they age is due to changes in the brain caused by tumors and strokes and other brain abnormalities.

\section{Aims and objectives}

To study clinical profile of seizure disorder in patients hospitalized in Coimbatore government medical college hospital.

\section{MATERIALS AND METHODS}

This study is a single center hospital based cross-sectional study of clinical profile of seizure disorder in patients hospitalized in Coimbatore government medical college. The study was conducted after receiving approval from the Institutional Human Ethics Committee. All patients presented with seizures were included in our study. Those unwilling to participate and those unavailable during the study period were excluded from the study. The study was conducted over a period of 2 year.

\section{Statistical analysis}

Statistical analysis was carried out for 321 patients with complaints of seizures. Statistical analysis was done using SPSS version 21, and the results are expressed in percentages.

\section{RESULTS}

A total of 321 patients were included in the study out of which 24 patients were from 10 to 20 years of age group, 21 patients were from 20 to 30 years of age group, 33 patients were from 30 to 40 years of age group, 42 patients were from 40 to 50 years of age group, 63 patients were from 50 to 60 years of age group, 54 patients were from 60 to 70 years of age group, 42 patients were from 70 to 80 years of age group, 30 patients were from 80 to 90 years of age group, 12 patients were from 90 to 100 years of age group. Maximum number of the patients were in 50-60 years and least number of the patients were in 90-100 years. The prevalence of active epilepsy is $6.4 / 1,000$ and the lifetime prevalence is $7.6 / 1,000$. The prevalence tends to increase with age, with peaks in the oldest age groups and in socially deprived individuals. The incidence of epilepsy is $61.4 / 1,00,000$ person-years. Epilepsy has a bimodal distribution according to age with peaks in the youngest individuals and in the elderly. ${ }^{5}$ The increased incidence of seizures and epilepsy in the elderly can be attributed to the increase of age-related and aging-related epileptogenic conditions (Table 1).

A total of 321 patients of which 180 were males and 141 females. Even though there is no overall gender difference in seizure disorder. In our study, seizure disorder was more in males. Overall, no gender difference was found in localization-related epilepsy, but localization-related symptomatic epilepsies were more frequent in men, and cryptogenic localization-related epilepsies were more frequent in women (Figure 1).

\begin{tabular}{lc} 
Table 1: Age distribution \\
\hline Age & Number of patients \\
\hline $10-20$ & 24 \\
$20-30$ & 21 \\
$30-40$ & 33 \\
$40-50$ & 42 \\
$50-60$ & 63 \\
$60-70$ & 54 \\
$70-80$ & 42 \\
$80-90$ & 30 \\
$90-100$ & 12 \\
\hline
\end{tabular}

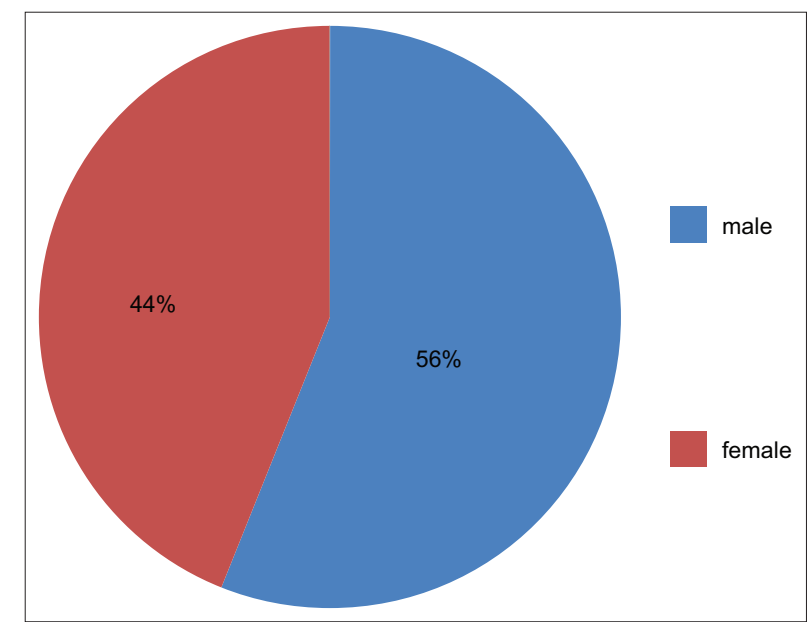

Figure 1: Sex distribution 
The relationship between alcohol and seizures is complex and multifaceted. The seizure threshold is raised by alcohol drinking and declines on cessation of drinking. As a result, during withdrawal from alcohol, usually $6-48 \mathrm{~h}$ after the cessation of drinking, seizures may occur. Alcohol acts on the brain through several mechanisms that influence seizure threshold. These include effects on calcium and chloride flux through the ion-gated glutamate NMDA and GABA receptors. During prolonged intoxication, the CNS adapts to the effects of alcohol, resulting in tolerance; however, these adaptive effects seem to be transient, disappearing after alcohol intake is stopped. Although the relationship of seizures to alcohol use is likely to be dose dependent and causal, the available clinical data do not suggest that alcohol use results in seizure genesis. ${ }^{6}$ However, a genetic predisposition to alcohol withdrawal seizures is possible.

The ingredients and chemicals in cigarettes could increase problems with the central nervous system. Be proconvulsant and other times anticonvulsant. Pose serious risks for people who already are epileptic. Cause seizures in those who have never suffered an epileptic episode before. In our study, the following chart indicates percentage of smokers, alcoholic, and non alcoholic (Figure 2).

\section{Last seizure episode}

About $30 \%$ of patients had new onset seizures. $20 \%$ patients had seizure 6 months back. $15 \%$ had last seizure episode 1 year back. Few did not remember there last seizure episode. $4 \%$ patients had seizure episode within 1 week.

\section{Seizure provocative factor}

In most of the cases seizure occurs spontaneously, but there may be association with various triggers. These triggers may act as seizure precipitating factors (SPFs). All participants were interviewed through a predesigned close ended questionnaire that included a long list of 20 precipitating factors. Fever precipitated seizure in 16\% of the subjects. A good number of them $17 \%$ noticed that whenever there was sleep deprivation, they had an attack of epilepsy. However, drug withdrawal, playing outside and head trauma were also common among the patients, about $15 \%, 8 \%$ and $12 \%$, respectively. The most of the patients can identify their seizure precipitant and clustering of many SPFs suggests a common pathophysiologic mechanism for these triggers. ${ }^{7}$ Excitation, sleep deprivation, fever, watching television, and head trauma showed a strong association with generalized epilepsy. Patients with seizure disorder should be evaluated for presence of SPFs, because identification of these might help in proper management of epilepsy. Patients' knowledge of seizure precipitants was poor. The majority of hospital admissions for seizures in epileptic patients are associated with potentially preventable causes amenable to education programs. Patient education involving epilepsy nurse educators may play an important role in decreasing seizure occurrence and possibly unnecessary hospital admissions (Figure 3).

\section{Demography}

In our study population, $75 \%$ of patients fall under low socioeconomic group and $73 \%$ of people are uneducated. Hence, uneducation and low socioeconomy make people vulnerable to seizures because of lack of awareness, poor compliance to medicines, not detection of seizure provoking factor, repeated exposure to seizure provoking factor, prevalence of alcoholism and thus lowering seizure threshold etc.

\section{Types of seizures}

Seizures were broadly classified in to 3 types Focal seizures, generalized seizures and lastly unclear epileptic spasm. Focal seizures can be classified in to focal seizures with intact awareness and impaired awareness. Generalized seizures were again classified into 5 types they are (1) absence seizures, (2) Tonic-clonic seizure, (3) clonic, (4) Atonic, and (5) Myoclonic seizure. Among total of 321 patients in our study 45 patients had focal seizures,

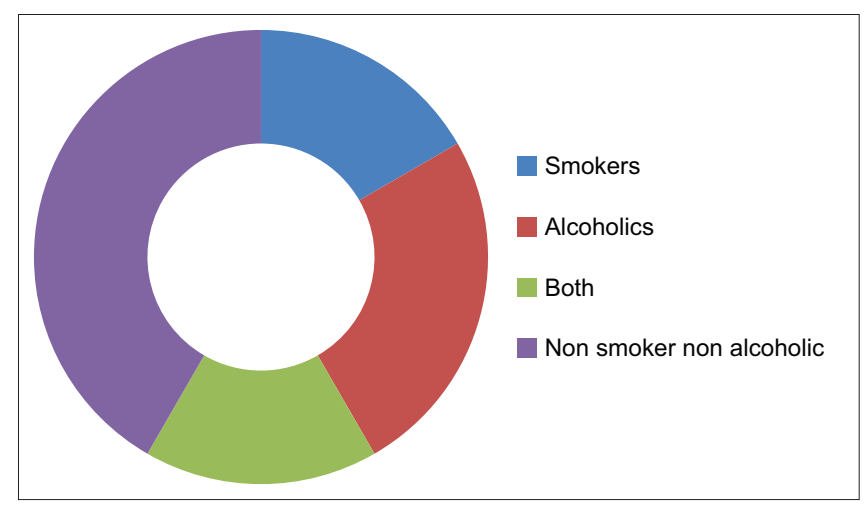

Figure 2: Smoking and alcohol distribution

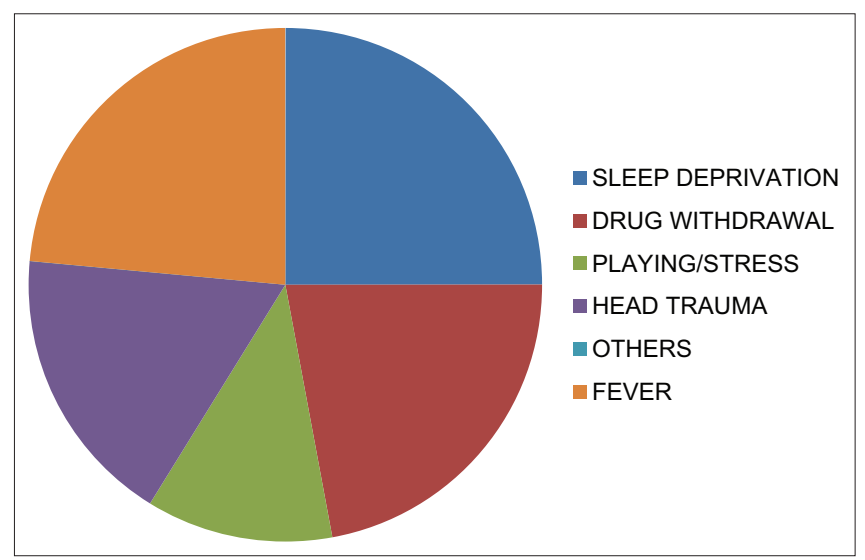

Figure 3: Seizure provocative factor 
210 patients had generalized seizures and others were unclear epileptic spasm.

\section{Provoked versus unprovoked seizure}

A provoked seizure has a direct cause such as a head injury, an infection or low blood sugar. An unprovoked seizure does not have an immediate cause. In our study, about 80 patients had provoked seizures out of 321 patients. Moreover, 241 patients had unprovoked seizure. Provoked seizures contribute to $25 \%$ of seizures.

\section{Past medical illness}

Many medical illnesses can cause seizures. Metabolic derangements, such as disorders of serum glucose metabolism, cause seizures, as well as other neurologic manifestations. In our study, out of 321 patients 159 patients were diabetics among diabetics 93 were male and 66 were female; there were 141 hypertensive patients out of which 81 were females and 60 were males. There wasabou $72 \mathrm{CKD}$ patients out of which 21 patients were on hemodialysis. 12 diabetic patients came with hyperglycemia and focal seizures. 36 patients had history of RTA. 45 patients had CVD. 6 patients had developmental delay.

\section{Clinical profile}

Almost all patients with generalized seizures had postictal confusion. Maximum duration of postictal state was about $24 \mathrm{~h}$ and minimum duration of postictal state was about 30 min. 45 patients had slurring of speech. 78 patients had neck stiffness. 45 patients had fecal incontinence. 135 patients had focal neurological deficit. 54 patients have bitten there tongue.

\section{Drug withdrawal seizures}

Patients who are on antiepileptics are at high chance of getting seizure if they suddenly stop antiepileptic drug. In our study, 18 patients who were on anti-epileptic drugs (AEDs) presented with seizures due to stoppage of medication.

\section{Response to treatment}

About $98 \%$ of patients responded to treatment and they did not had recurrent episodes of seizure. $2 \%$ had refractory seizures. All patients were monitored for $48 \mathrm{~h}$ for any recurrent episodes of seizures. The sample size of our cohorts is relatively small. It is possible that some prognosis factors may be missed due to the small sample size. Further, studies with a larger sample cohort are required.

\section{Brain imaging}

Due to lack of resources imaging was not done in all patients. Among our study patients, 198 patients underwent CT and 60 patients underwent MRI imaging. 135 patients had normal study. 60 patients had acute or chronic infarct. Brain edema was found in 57 patients. Ideally, MRI brain with epilepsy protocol should have been investigation of choice but because of practical constraints MRI was not done in all patients.

\section{EEG}

Sixty six patients had abnormal epileptiform activity in EEG. 105 patients had normal EEG study. A few patients missed EEG.

Maximum number of the patients presenting with seizure were being diagnosed as stroke and tumors being least cause for seizure (Table 2).

\section{DISCUSSION}

Neurological diseases are the most common disease among all the diseases in the word and among that seizure disorder

\section{Table 2: Age distribution of adult onset seizures}

\begin{tabular}{|c|c|c|c|c|c|c|c|}
\hline \multirow[t]{2}{*}{ Diagnosis } & \multicolumn{6}{|c|}{ Age distribution (years) } & \multirow[t]{2}{*}{ Total } \\
\hline & Under 20 & $21-30$ & $31-40$ & $41-50$ & $51-60$ & Above 60 & \\
\hline Stroke & 2 & 5 & 6 & 12 & 25 & 36 & 86 \\
\hline Percentage & & & & & & & 26 \\
\hline CNS infection & 8 & 5 & 5 & 6 & 14 & 18 & 56 \\
\hline Percentage & & & & & & & 17 \\
\hline Metabolic & 9 & 4 & 7 & 8 & 7 & 26 & 61 \\
\hline Percentage & & & & & & & 19 \\
\hline Brain tumors & 1 & & 2 & & 3 & 7 & 13 \\
\hline Percentage & & & & & & & 4 \\
\hline CVT & & 4 & 6 & 4 & 4 & 8 & 26 \\
\hline Percentage & & & & & & & 8 \\
\hline ADEM & & & 2 & 4 & 4 & 12 & 22 \\
\hline Percentage & & & & & & & 6 \\
\hline PRES & & & 1 & 2 & 2 & 6 & 11 \\
\hline Percentage & & & & & & & 3 \\
\hline Percentage & & & & & & & 14 \\
\hline Total & 24 & 21 & 33 & 42 & 63 & 138 & 321 \\
\hline
\end{tabular}


is one of the most common disease causing morbidity and premature mortality. The spectrum of seizure disorder varies based on demographic profile of the patients. Hence, the knowledge of profile of patients in different clinicosocial environment is a necessity. Infections (neurocysticercosis, tuberculoma, meningitis, and malaria) were the hidden spurious causes followed by idiopathic. In the study by Quraishi et al., ${ }^{8}$ tuberculoma accounts for $14 \%$ and in Thapa et al., ${ }^{9}$ study, it accounts for $10 \%$. The incidence was high in studies of Ramamurthi et al., $(19.4 \%)^{10}$ In this study, alcohol related seizures formed $15 \%$ of cases. the findings of Rathlev et al., ${ }^{11}$ where $53.6 \%$ patients had causes other than alcohol withdrawal. Maximum number of the patients presenting with seizure were being diagnosed as stroke $25 \%$ either acute or chronic and tumors being least cause for seizure. In $>65$ years age, vascular causes were the most common. In 18-25 years age group, Infections (neurocysticercosis, tuberculoma, meningitis, and malaria) were the most common cause followed by idiopathic. In middle $26-45$ years age group, infections such as neurocysticercosis, tuberculoma, meningitis, malaria, and toxoplasma were the most common cause followed by idiopathic followed by vascular which included arterial and venous infarcts and intracranial bleed. GTCS was the most common type of seizure cases.

\section{Limitations of the study}

Some prognosis factors may be missed due to the small sample size.

\section{CONCLUSION}

Epilepsy is a common neurological problem. It can profoundly affect life of people. The sample size of our cohorts is relatively small. It is possible that some prognosis factors may be missed due to the small sample size. Further, studies with a larger sample cohort are required. Uneducation and low socioeconomy make people vulnerable to seizures because of lack of awareness, poor compliance to medicines, not detection of seizure provoking factor, repeated exposure to seizure provoking factor, prevalence of alcoholism, and thus lowering seizure threshold. There is a treatment gap still because of epilepsy and appropriate usage of resources will help to reduce this treatment gap and decreases epilepsy associated morbidity and mortality.

\section{ACKNOWLEDGMENT}

The authors extend their sincere thanks to the Departments of Neurology and General Medicine for their support to conduct the study.

\section{REFERENCES}

1. Fisher Rs, Acevedo C, Arzimanoglou A, Bogacz A, Cross JH, Elger CE, et al. A practical clinical definition of epilepsy. Epilepsia. 2014;55(4):475-82.

https://doi.org/10.1111/epi.12550

2. Kinnier Wilson JV and Reynolds EH. Translation and analysis of a cuneiform text forming part of a Babylonian treatise on epilepsy. Med Hist. 1990;34(2):185-198.

https://doi.org/10.1017/s0025727300050651

3. Changb BS and Lowenstein DH. Epilepsy. N Engl J Med. 2003;349:1257.

https://doi.org/10.1056/NEJMra022308

4. Lowensteindh $\mathrm{DH}$ and Alldredge BK. Status epilepticus. N Engl J Med. 1998;338(14):970.

https://doi.org/10.1056/NEJM199804023381407

5. Noebels JL. Exploring new gene discoveries in idiopathic generalized epilepsy. Epilepsia. 2003;44(Suppl 2):16

https://doi.org/10.1046/j.1528-1157.44.s.2.4.x

6. Fisher RS, Cross JH, D'Souza C, French JA, Haut SR, Higurashi N, et al. Instruction manual for the ILAE 2017 operational classification of seizure types. Epilepsia. 2017;58(4):531-42. https://doi.org/10.1111/epi.13671

7. Wiebe S, Blume WT, Girvin JP, Eliasziw M and Effectiveness and Efficiency of Surgery for Temporal Lobe Epilepsy Study Group. A randomized, controlled trial of surgery for temporallobeepilepsy. N Engl J Med. 2001;345(5):311-318. https://doi.org/10.1056/NEJM200108023450501

8. Quraishi SM, Rani U, Prasanthi P and Sudhakar P. Etiological profile of new onset seizures. J Evid Based Med Healthc. 2015;2:7032-7044.

https://doi.org/10.18410/jebmh/2015/960

9. Thapa L, Shrestha A, Paudel R, Pokharel BR, Ghimire A, Shilpakar $\mathrm{R}$, et al. Clinical and socio-economic factors among epileptic patients in Nepal: A big challenge. J Coll Med Sci Nepal. 2012;7(2):29-33. https://doi.org/10.3126/jcmsn.v7i2.6677

10. Ramamurthi B, Ramamurthi $R$, Vasudevan $M C$ and Sridhar K. The changing face of tuberculomas. Ann Acad Med Singap. 1993;22(6):852-855.

11. Rathlev NK, Ulrich A, Shieh TC, Callum MG, Bernstein E and D'Onofrio G. Etiology and weekly occurrence of alcohol-related seizures. Acad Emerg Med. 2002;9(8):824-8.

https://doi.org/10.1197/aemj.9.8.824

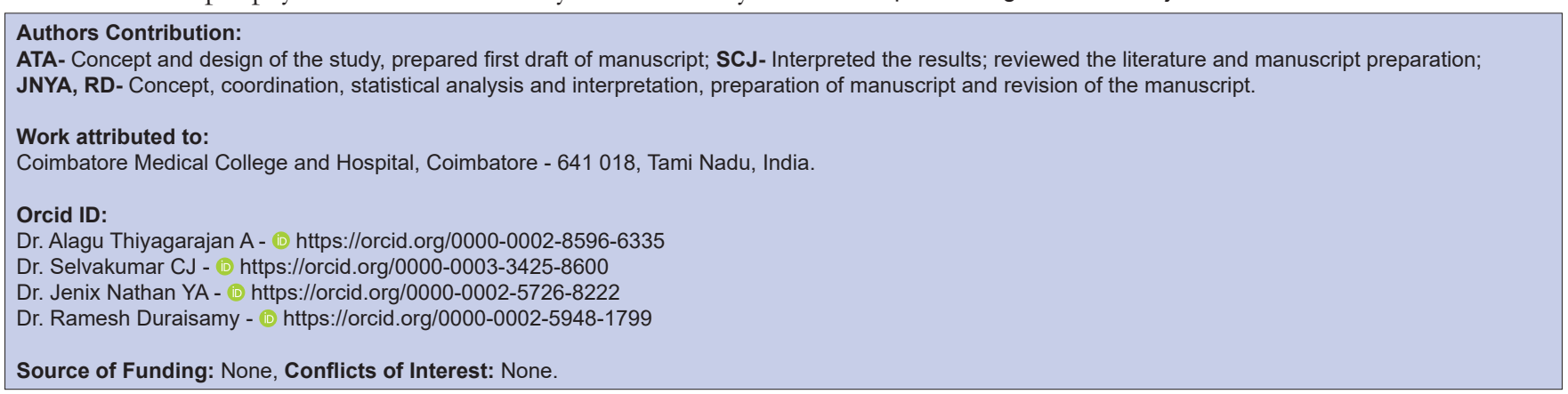

